Article

\title{
Research on the Spatial Differentiation and Driving Factors of Tourism Enterprises' Efficiency: Chinese Scenic Spots, Travel Agencies, and Hotels
}

\author{
Bing Xia ${ }^{1,2,3}$, Suocheng Dong ${ }^{1, *}$, Duoxun Ba ${ }^{3}, \mathrm{Yu} \mathrm{Li}^{1}{ }^{1}$, Fujia Li ${ }^{1}$, Haimeng Liu ${ }^{1}$ (D), \\ Zehong $\mathrm{Li}^{1}$ and Minyan Zhao ${ }^{1}$ \\ 1 Institute of Geographic Sciences and Natural Resources Research, Chinese Academy of Sciences, \\ Beijing 100101, China; xiab.16b@igsnrr.ac.cn (B.X.); liy@igsnrr.ac.cn (Y.L.); lifj@igsnrr.ac.cn (F.L.); \\ liuhm.14b@igsnrr.ac.cn (H.L.); lizehong@igsnrr.ac.cn (Z.L.); my.z@yeah.net (M.Z.) \\ 2 College of Resources and Environment, University of Chinese Academy of Sciences, Beijing 100049, China \\ 3 Tourism College, Northwest Normal University, Lanzhou 730070, China; baduoxun@163.com \\ * Correspondence: dongsc@igsnrr.ac.cn; Tel.: +86-18-801-012-554
}

Received: 1 February 2018; Accepted: 12 March 2018; Published: 21 March 2018

check for updates

\begin{abstract}
Tourism is an important sustainable industry in the economy that optimizes the industrial structure. Thus, as a core part of this market, tourism enterprises perform a key role in the effective operation of this industry. This paper applies data envelopment analysis (DEA) and Malmquist index (MI) models to calculate the efficiency of Chinese tourism enterprises between 2005 and 2014. Results showed that: (1) The efficiency and the total factor productivity change index (TFPC) of tourism enterprises remained low, and both have decreased. (2) The efficiency of regional tourism enterprises across China cloud be characterized as high in the east region, low in the central region, and high in both northeast and western regions. (3) The efficiency levels of the cities of Beijing and Shanghai were ahead of the country over the period of this study, while Chongqing, Tibet, Qinghai, and Ningxia all possess a number of obvious advantages in the western region. (4) Centers of overall tourism enterprise efficiency mainly moved in a southeast-to-northwest direction over the period of this research. (5) The spatial autocorrelation of tourism enterprise efficiencies is also assessed in this study, and the results show that the comprehensive efficiency (CE) of tourism enterprises in southeastern coastal regions of China tended to a certain spatial agglomeration effect, while the correlation between the central region and northern China was not significant. (6) The Geodetector model is applied to analyze the key factors driving the spatial differentiation of tourism enterprise efficiencies, and the results show that the degree of opening to the outside world, potential human capital, and traffic conditions were the most important factors driving spatial differentiation in the efficiency of tourism enterprises.
\end{abstract}

Keywords: efficiency of tourism enterprises; spatial differentiation; DEA-Malmquist; spatial autocorrelation; Geodetector

\section{Introduction}

The tourism industry has played an important role in sustainable development globally. It benefits almost all of the sustainable goals announced by the United Nations in 2015 [1]. China became the world's largest source of tourists in 2013, while in 2015 remained just the fourth largest destination country in the world. Chinese tourism therefore presents an overall "trade deficit", as more than 292 billion dollars are spent on outbound travel, while 114 billion dollars are generated in inbound income [2]. A large gap nevertheless remains in terms of service facilities, quality, and the overall tourism experience between China and other leading tourism development countries, such as France, 
the United States, and Spain. It is undeniable that the gap between China's tourism enterprises and the world's first-class tourism enterprises is also very large. In addition, rapid globalization and the development of information flow has also weakened the intermediary function of travel agencies, while some scenic spots have been overloaded with "blowout" phenomenon due to the optimal layout of fast traffic networks. As a result of globalization, the competition between Chinese hotels and other international hospitality groups is becoming increasingly fierce. Efficiency, as the method of evaluating the production target with the most effective use of resources under given input and technology, is therefore the endogenous driving force of enterprise development. This variable can reflect resource allocation and arrangement of an enterprises as well as objectively reflect the developmental state and future potential. Tourism enterprises refer to travel agencies, scenic spots, and enterprises providing transportation, accommodation, catering, shopping, entertainment and other services sectors for the tourists. In this context, scenic spot travel agencies (for both local people and incoming tourist) and hotel are included. The efficiency of tourism enterprises can include comprehensive, technical, and scale components of this variable, as well as total factor productivity.

Previous research on tourism efficiency has mainly focused on macro scale regional tourism [3-5], meso-scale industry, city cases [6-9], national parks, scenic spots and resorts [10-12]. The tourism efficiency research fields include the performance of destination [13,14], cultural tourism [15], the eco-efficiency [7], energy efficiency [16,17], resources efficiency and water efficiency [18] of the tourism destination, hotels $[19,20]$ and even tourist [21], as well as the education efficiency of tourism [22,23], tourism supply chains [24], tourism events [25], communicative efficiency [26], tourism channel, trade shows [27] and customer satisfaction [28,29]. In contrast, research on the efficiency of tourism enterprises or sectors have mainly focused on the efficiency of the hotels [30-32], travel agencies [33], tourism transportation departments [34,35] and museums [36,37]. The kinds of research projects that have been carried out have included the construction of input-output systems for tourism efficiency, the innovation of efficiency evaluation [38,39], analysis of total factor productivity within the industry [40], analysis of tourism efficiency spatial regularity [41,42], and the factors that drive efficiency $[43,44]$. In contrast, the main research methods applied include both parametric and non-parametric methods. The formaer has mainly been based on the Bayesian approach of the stochastic frontier analysis [45-48], while DEA has mainly been applied in the case of non-parametric estimations [49-52].

Research on tourism efficiency has led to several significant steps forward in both methods and content. Investigations on the efficiency of tourism enterprises, for example, have mainly focused on the efficiency of single tourism sector, while little wider overall research integrating scenic spots, travel agencies, and hotels has been carried out. Indeed, analysis of the factors driving the efficiency of tourism enterprises has rarely been carried out from a space perspective. Thus, compared with the tourism industry, assessing the statistical value of enterprises can be more objective. Research on the efficiency of tourism enterprises also avoids the problem of higher tourism output values because of the industry multiplier effect and the fact that the quality and potential of this industry, especially market development, can be more objectively illustrated. Spatial correlation research and the analysis of factors driving these spatial patterns are of great significance because of the cross-spatial scale characteristics of tourism services and products.

The DEA and MI models were adopted in this paper to integrate three elemental sectors of tourism, namely, scenic spots, travel agencies, and hotels, by analyzing the efficiency and total factor productivity of Chinese tourism enterprises. The spatial correlation and concentration level of comprehensive efficiency of tourism enterprises was be analyzed by Moran's I. The factors underlying and driving these variables are also assessed by applying the Geodetector method developed by the Chinese scholar Wang [53].

Clearly, both the level of market perfection and the maturity of the main bodies within the economy are important prerequisites that will guarantee sustainable tourism development and the attainment of an international leading position. Through the efficiency analysis of tourism enterprises, 
we can objectively and accurately evaluate the development potential of tourism market from the perspective of industrial supply; this process will be beneficial if the current development dilemma in the Chinese tourism industry is to be broken and will also provide endogenous impetus for further development.

\section{Methods}

\subsection{The DEA Model}

This paper applied the CCR Model based on constant returns to scale and the BBC Model based on variable returns to scale to measure the Comprehensive Efficiency (CE), Pure Technology Efficiency (PTE) and Scale Efficiency (SE) of China's tourism enterprises [54,55].

This study assumed that there were $m$ investment indicators within $n$ provinces and $s$ output indicators that measure the efficiency of tourism enterprises, expressed as $X_{j}$ and $Y_{j}$, as follows [54]:

$$
X_{j}=\left(x_{1 j}, x_{2 j}, \cdots, x_{m j}\right)^{T}, Y_{j}=\left(y_{1 j}, y_{2 j}, \cdots, y_{s j}\right)^{T}, j=1,2, \ldots, n
$$

where $x_{i j}(>0)$ denotes the input amount of the $i$ type input indicator in $j$ province, while $y_{r j}(>0)$ denotes the output amount of $r$ type input indicator in $j$ province. Thus, $I=1,2, \ldots, m ; r=1,2, \ldots, s$; and $j=1$, $2, \ldots, n$. The formula for calculating the CCR model is therefore as follows [55]:

$$
\begin{cases}\min & {\left[\theta-\varepsilon\left(e^{T} s^{+}+\hat{e}^{T} s^{-}\right)\right]} \\ \text {s.t. } & \sum_{j=1}^{n} X_{j} \lambda_{j}+s^{-}=\theta X_{0} \\ & \sum_{j=1}^{n} Y_{j} \lambda_{j}-s^{+}=\theta Y_{0} \\ & \lambda_{j} \geq 0, j=1,2, \cdots, n \\ & s^{-} \geq 0, s^{+} \geq 0\end{cases}
$$

where $\theta(0<\theta \leq 1)$ denotes the $C E$ index. Thus, a situation where $\theta=1$ means that the $C E$ of tourism enterprises within this province has reached the best production frontier, and that similar values for input and output are also optimal, reflecting the efficiencies of all kinds of production factors in enterprises. Similarly, $\lambda_{j}$ denotes a weight variable $\left(\lambda_{j} \geq 0\right), \varepsilon$ is the Archimedes infinitesimal, $s^{-}$is the input slack variable, $s^{+}$is the remain variable of output, $e^{T}=(1,1, \cdots, 1) \in E_{s}$ and $\hat{e}^{T}=(1,1, \cdots, 1) \in E_{m}$ denote the $s$ and $m$ dimension unit vector spaces, and $X_{0}$ and $Y_{0}$ are the input and output vectors of tourism enterprises in different provinces. This model is then converted to the BCC form by adding $\sum_{j=1}^{n} \lambda_{j}=1$ as constraints into the formula, while the CE of tourism enterprises can be divided into the product of PTE and SE. The latter is then used to measure the output level unit input of tourism enterprises, reflecting the scale of a given enterprise, while PTE is used to assess whether a given tourism initiative is able to effectively make use of production technology to maximize unit outputs, an indication of business management level. Values of CE, PTE, and SE are within 0-1.

\subsection{Malmquist Index}

The MI was initially proposed by Sten Malmquist [56] and was first applied for the measurement of productivity changes by Caves [57]. Researchers often combine this index with the DEA model to measure changes in relative efficiency. The exponential MI construction process is discussed below.

Given the technical conditions of a period, $t$, changes in comprehensive efficiency from this time point to $t+1$ are expressed as follows [57]:

$$
M^{t}=\frac{D_{C}^{t}\left(x^{t+1}, y^{t+1}\right)}{D_{C}^{t}\left(x^{t}, y^{t}\right)}
$$


Similarly, under the technical conditions of the $t+1$ period, changes in CE between $t$ and $t+1$ period are expressed as follows [57]:

$$
M^{t+1}=\frac{D_{C}^{t+1}\left(x^{t+1}, y^{t+1}\right)}{D_{C}^{t+1}\left(x^{t}, y^{t}\right)}
$$

Thus, applying the geometric mean number of the above two Malmquist productivity indexes to calculate total factor productivity (TFP) between the $t$ period and the $t+1$ period, MI can be calculated as follows [57]:

$$
M\left(x^{t}, y^{t}, x^{t+1}, y^{t+1}\right)=\sqrt{M^{t} \times M^{t+1}}
$$

Applying the model as proposed by Fare [58], MI expressed in the form of total factor productivity change (TFPC) can therefore be further decomposed into technological change (TC) and technical efficiency change (TEC), while comprehensive efficiency change (CEC) can be decomposed into pure technical efficiency change (PTEC) and scale efficiency change (SEC) components as follows [57]:

$$
\begin{aligned}
M\left(x^{t}, y^{t}, x^{t+1}, y^{t+1}\right) & =\frac{D_{V}^{t+1}\left(x^{t+1}, y^{t+1}\right)}{D_{V}^{t}\left(x^{t}, y^{t}\right)} \times \sqrt{\frac{D_{C}^{t}\left(x^{t}, y^{t}\right)}{D_{C}^{t+1}\left(x^{t}, y^{t}\right)} \times \frac{D_{C}^{t}\left(x^{t+1}, y^{t+1}\right)}{D_{C}^{t+1}\left(x^{t+1}, y^{t+1}\right)}} \times \frac{D_{C}^{t+1}\left(x^{t+1}, y^{t+1}\right) / D_{V}^{t+1}\left(x^{t+1}, y^{t+1}\right)}{D_{C}^{t}\left(x^{t}, y^{t}\right) / D_{V}^{t}\left(x^{t}, y^{t}\right)} \\
& =\operatorname{PTEC} \times \operatorname{TC} \times \operatorname{SEC}=\operatorname{TC} \times \operatorname{TEC}
\end{aligned}
$$

As discussed, the MI was used to measure the TFPC of tourism enterprises; thus, when a value for this index is greater than 1, TFP is increasing and efficiency is improving. Values for CEC reveal the degree of $C E$ change in tourism enterprises and are used to assess comprehensive management level, while TC values indicate the degree of change in technological progress, and are used to measure technological and innovation levels. Moreover, TEPC values can be used to reflect improvements in production efficiency due to technological progress, jointly reflecting the application of science and technology and the future development potential of tourism enterprises. A total of eight indexes were therefore used in this study (i.e., CE, PTE, SE, CEC, PTEC, SEC, TFPC, and TC) to assess the efficiency levels of Chinese tourism enterprises.

\subsection{Spatial Autocorrelation Analysis}

Thus, spatial correlations between tourism enterprise CE values within the different provinces of China were discussed in this study using both global and local spatial autocorrelation analysis. Global autocorrelation is usually measured via global Moran's I which can output a range of values between -1 and 1 . A positive value in this case indicates positive spatial correlation, and vice versa, while a zero value indicates no correlation, a random spatial distribution. The equation used to calculate Moran's I is as follows [59]:

$$
I=\frac{n \sum_{i=1}^{n} \sum_{j=1}^{n} w_{i j}\left(y_{i}-\bar{y}\right)\left(y_{j}-\bar{y}\right)}{\left(\sum_{i=1}^{n} \sum_{j=1}^{n} w_{i j}\right) \sum_{i=1}^{n}\left(y_{i}-\bar{y}\right)^{2}}
$$

where $n$ denotes the number of included observations, while $w y_{i}$ and $y_{j}$ denote the attribute values of objects in space $i$ and space $j, \bar{y}$ is the average attribute value of the whole area, and the spatial weighting matrix $\left(w_{i j}\right)$ denotes the adjacency of two elements. The global Moran's I index is then used to test the significance level of spatial correlations by applying $Z$ test statistics as follows [59]:

$$
\mathrm{Z}=\frac{I-E(I)}{\sqrt{\operatorname{Var}(I)}}
$$

where $E(I)$ denotes expectation and $\operatorname{Var}(I)$ is variance. However, because global spatial autocorrelation assumes homogeneous space, it is also necessary to analyze the degree of spatial correlation within each 
space object via local spatial autocorrelation. The global Moran's I index was therefore decomposed into local space, and a local version was calculated as follows [59]:

$$
I_{i}=\frac{y_{i}-\bar{y}}{S^{2}} \sum_{j=1}^{n} w_{i j}\left(y_{i}-\bar{y}\right)
$$

where $S^{2}$ denotes the discrete variance of $y_{i}, \bar{y}$ is the mean value, and $w_{i j}$ refers to the weight matrix. A positive value of $I_{i}$ indicates the presence of similar spatial aggregation (i.e., high-high or low-low) areas around the region in question, while a negative $I_{i}$ value indicates the reserve (i.e., high-low or low-high).

\subsection{Geodetector Analysis}

The statistical Geodetector method enables the detection of spatial diversity, can be used to reveal driving forces, and can verify the spatial heterogeneity of single variable. This approach can also be used to detect possible causality between two variables by testing the consistency of their spatial distribution. This method involves the use of an index, $q$, that determines the efficiency of tourism enterprise spatial differentiation. This approach assumes that the efficiency of a tourism enterprise within an area, $I$, is $y$, and therefore that $A=\left\{A_{h}\right\}$ expresses the relationship between the factors that may affect the spatial differentiation of enterprise efficiencies. Therefore, $h=1,2, \ldots, L$, with $L$ denoting the number of categories of the factors, $A_{h}$ the different types of factor $A$, and with one type (h) corresponding to one or more sub-regions in the space. To detect spatial correlation between $A$ and $y$, we therefore overlapped the layers of these two variables as well as the $h$ type of factor $A$. As the discrete variance of $y$ is recorded as $\sigma_{h}^{2}$, the determination of factor $A$ is calculated as follows [53]:

$$
q=1-\frac{1}{n \sigma^{2}} \sum_{h=1}^{L} n_{h} \sigma_{h}^{2}
$$

where $n_{h}$ denotes the number of type $h$ of factor $A$, while $n$ refers to the number of all samples across the whole research area. As the $q$ range is $[0,1]$, a larger value indicates a stronger ability to explain changes in tourism industry efficiency factors. Thus, a numerical value of zero indicates that classification factors have nothing to do with the spatial differentiation of tourism enterprises' CE while a value of one indicates the opposite.

\subsection{Input-Output Indicators and Data}

Based on the sub-sectors that comprise tourism development, enterprises within this industry can be divided into scenic spots, travel agencies, hotels, souvenir retail businesses, catering, transportation services, and culture and entertainment enterprises. Thus, building on the existing research literature, data availability, and preliminary statistical analyses, this study mainly used provincial statistical data from three core sectors, scenic spots, travel agencies, and hotels, to test the level of efficiency of the core sectors and general enterprises. Fixed assets, number of employees, number of enterprises at scenic spots, travel agencies, and hotels were therefore used as input indicators, while the operating income of scenic spots, travel agencies, and hotels were used as output indicators in this analysis to evaluate the efficiencies of tourism enterprises. Although variable capital indicators such as food and beverage, as well as tourist satisfaction indicators should also be included in input-output indicators, considering the difficulty of data acquisition, they are not used in this article. The data used in this analysis were derived mainly from the Chinese Statistical Yearbook and the Chinese Tourism Statistics Yearbook between 2005 and 2014. Some analyses in this paper included 2010 for the missing data of scenic spots. 


\section{Results}

\subsection{CE Values and the Decomposition Efficiencies of Tourism Enterprises}

\subsubsection{The Efficiencies of Tourism Enterprises}

The efficiencies of tourism enterprises were calculated using Equation (2). It showed that overall efficiencies over time can be characterized by a general downward trend. Records show that the efficiencies of scenic spots in 2011 strongly fluctuated and then gradually stabilized, while those of travel agencies prior to 2009 remained relatively stable, and began to fluctuate subsequent to 2009, exhibiting a marked decline in 2013 and 2014. while the efficiency of hotels has remained relatively stable. Data reveal that overall CE and PTE values for tourism enterprises have remained less than 0.8, albeit increasing slightly over time, while SE values have remained relatively high, although on the whole trending downwards (Figure 1).

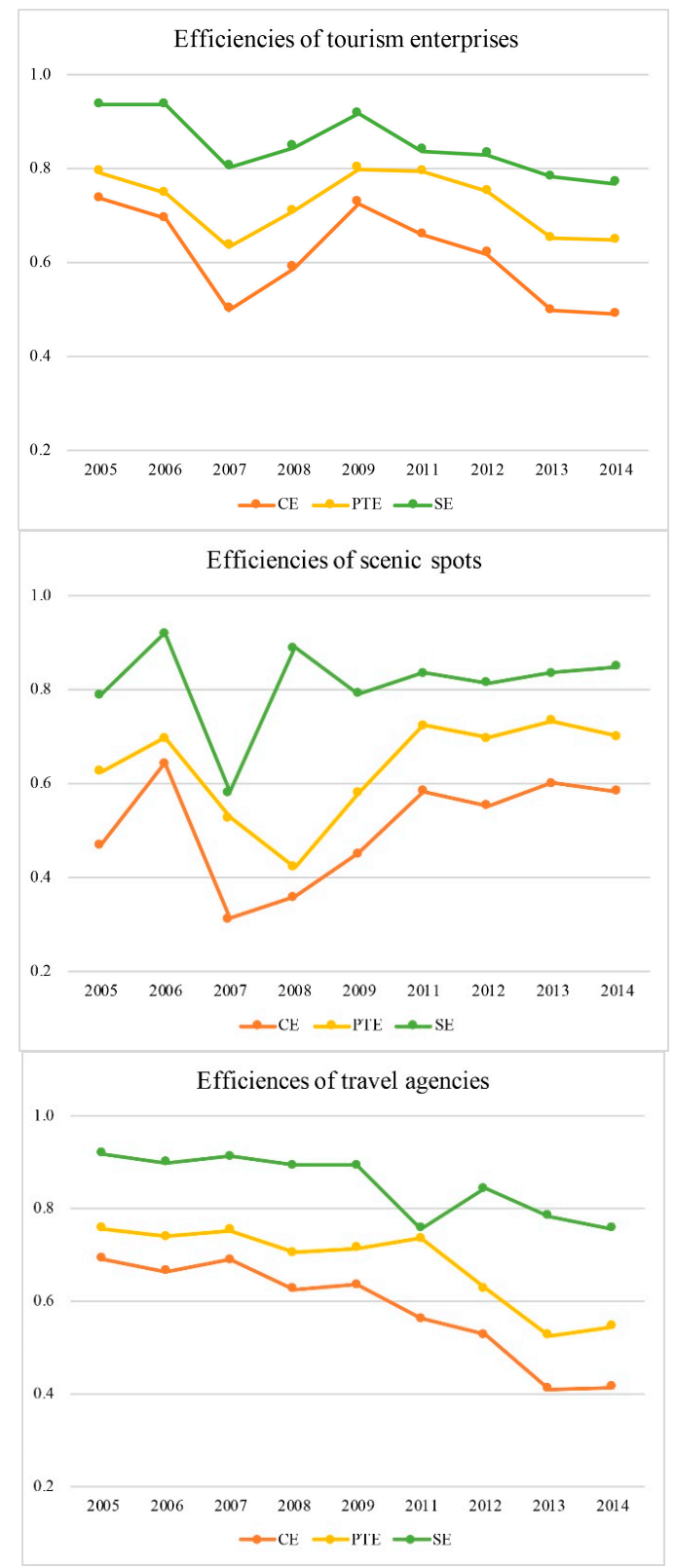

Figure 1. Cont. 


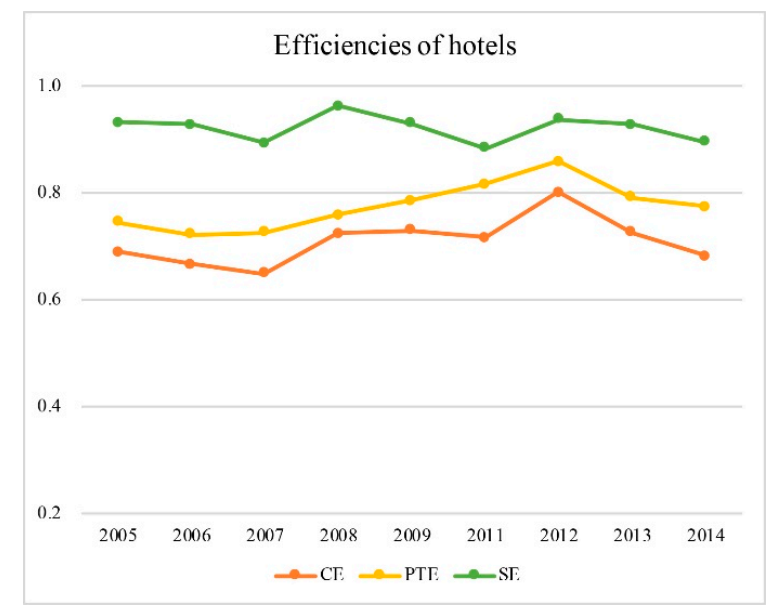

Figure 1. Efficiency values of Chinese tourism enterprises between 2005 and 2014.

\subsubsection{Correlations between PTE, SE and CE}

A series of scatter plots for the period 2005-2014 were assembled in this study using PTE, SE, and $C E$ values for tourism enterprises, scenic spots, travel agencies, and hotels. These data were then analyzed to determine correlations and the level of PTE and SE contributions to CE, respectively (Figure 2). These data show that, between 2005 and 2014, the correlation between tourism enterprises and the PE and CE of subindustries was higher than the SE and CE. Although SE values are higher than those for PTE, because of the limited contribution of scale efficiency to $\mathrm{CE}$, these values for tourism enterprises remain at a relatively low level. This result indicates that the efficiency level of tourism enterprises is more influenced by the PTE. It is necessary to further explore the application of modern technologies (e.g., mobile Internet and big data mining) to the tourism industry to realize cost reductions in tourism products and services as well as market expansion. Improving the pure technological efficiency of enterprises will also improve efficiency levels (Figure 2).

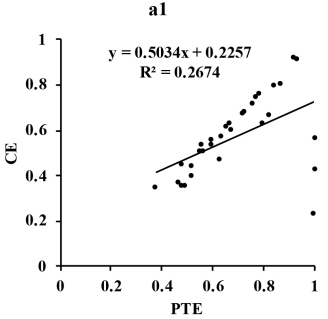

(a) Tourism enterprises

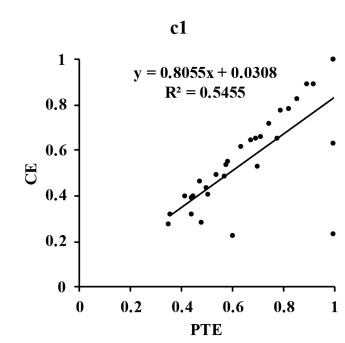

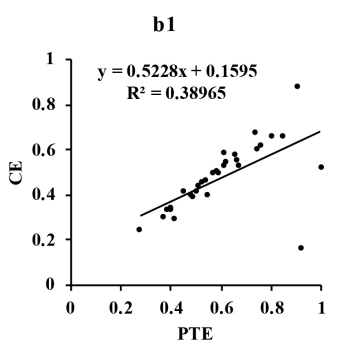

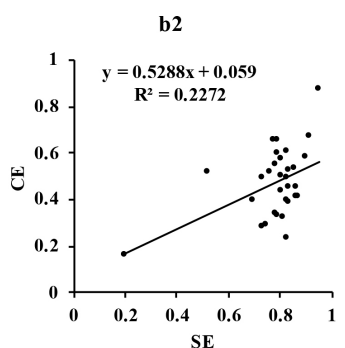

(b) Scenic spots

c2

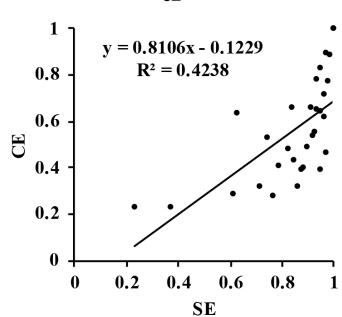

(c) Travel agencies
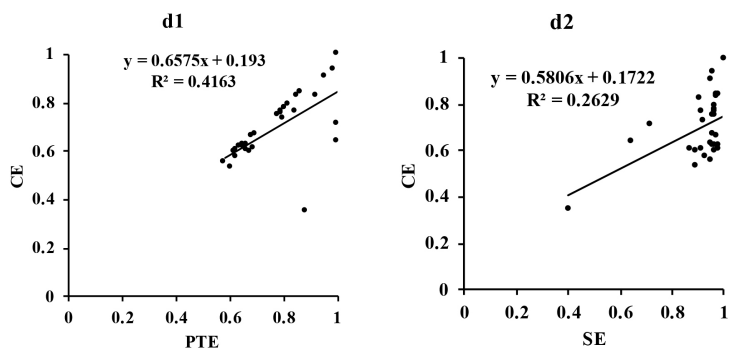

(d) Hotels

Figure 2. Scatter plots to show correlations between the PTE, SE and CE of Chinese tourism enterprises. 


\subsection{The Evolution of Spatial Patterns in Tourism Enterprise Efficiency}

\subsubsection{Coefficient of Variation}

Coefficient of variation $(\mathrm{CV})$ measures the degree of difference between regional efficiency levels. We found that the difference between $\mathrm{CE}$ values for tourism enterprises and travel agencies was bigger among the provinces. Data also show that differences in the CE between scenic spots and hotels was decreasing over time. The CV of tourism enterprise CEs increased from 0.264 in 2005 to 0.451 in 2014, the CV of travel agency CEs increased from 0.343 in 2005 to 0.604 in 2014; the CV of star hotels CEs decreased from 0.253 in 2005 to 0.229 in 2014; and the CV of scenic spots CEs decreased from 0.536 in 2005 to 0.409 in 2014 (Figure 3).

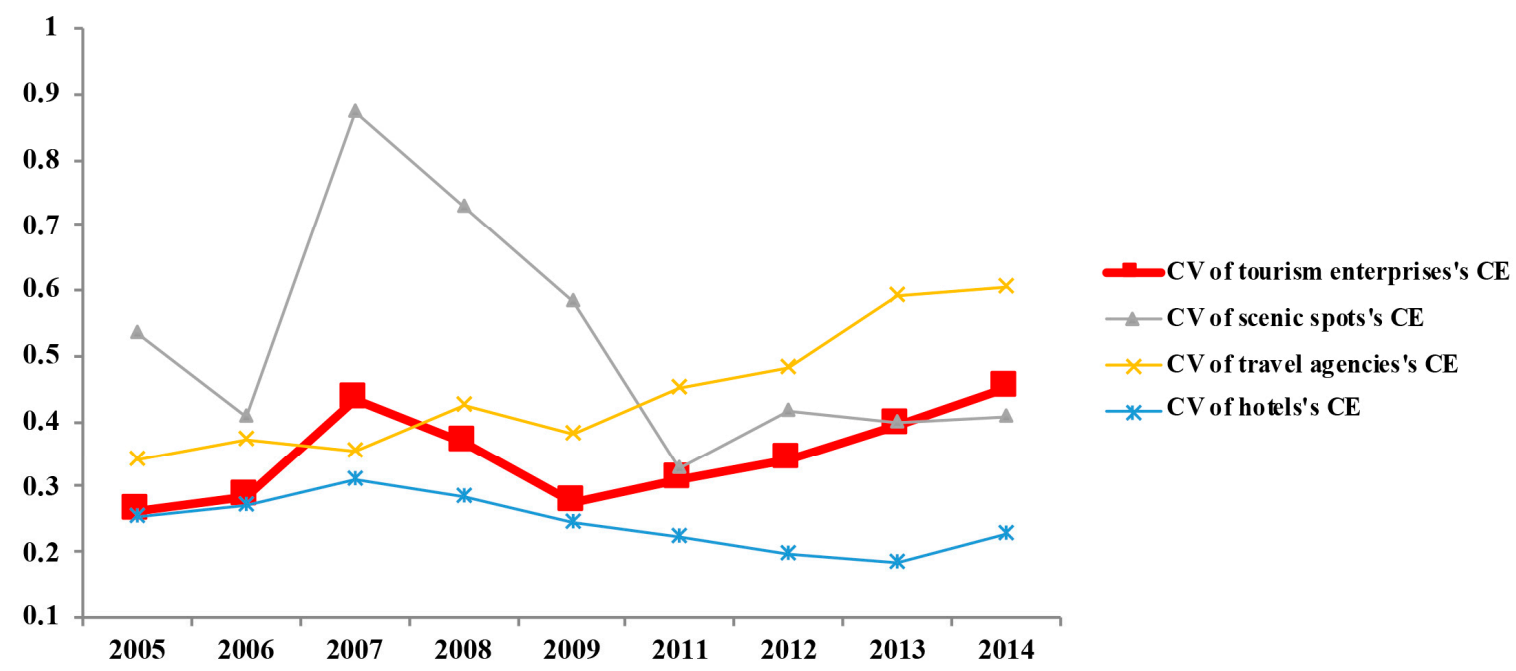

Figure 3. Trends of Chinese provincial tourism enterprises' CE differences between 2005 and 2014.

\subsubsection{Spatial Patterns in CE and the Decomposition Efficiencies of Tourism Enterprise}

The result presented in this paper reveal that the provinces of Beijing, Shanghai, and Chongqing all contain tourism enterprises with $\mathrm{CE}$ values of more than 0.8 . Similarly, eight provinces across China have PTE values above 0.8; in the east, these were Beijing, Tianjin, Shanghai, and Guangdong, while the rest were in the western region, including Chongqing, Tibet, Qinghai, and Ningxia. A total of 21 provinces had SE values higher than 0.8 , encompassing $67.7 \%$ of the whole country. The tourism scenic spots of 18 provinces were characterized by SE values higher than 0.8 , encompassing $58.1 \%$ of the country, while just a single province (Jiangxi) alongside another five (Shanghai, Jiangxi, Sichuan, Tibet, and Qinghai) contain scenic spots with CE and PTE values higher than 0.8. A total of 23 provinces had travel agency SE values that are higher than 0.8 , accounting for $74.2 \%$ of the country, while five (Beijing, Shanghai, Guangdong, Hunan, and Yunnan) and eight (Beijing, Shanghai, Guangdong, Hunan, Chongqing, Yunnan, Tibet, Ningxia) provinces had CE and PTE values higher than 0.8 for this sector, respectively. In terms of hotels, a total of 28 and 13 provinces were characterized by SE and PTE values greater than 0.8; these data encompassed seven provinces, including five in the east of the country (Beijing, Tianjin, Shanghai, Jiangsu, and Zhejiang), as well as two in the center of China (Shanxi and Henan) that also had CE values higher than 0.8. Beijing, Tianjin, and Shanghai have obvious advantages in terms of their tourism enterprise $C E$ values; high efficiency scenic spots were mainly concentrated in the center of China, while travel agencies with high values were mainly concentrated in the south. Data showed that high efficiency hotels areas were mainly concentrated in the southeast coastal area of China (Figure 4). 

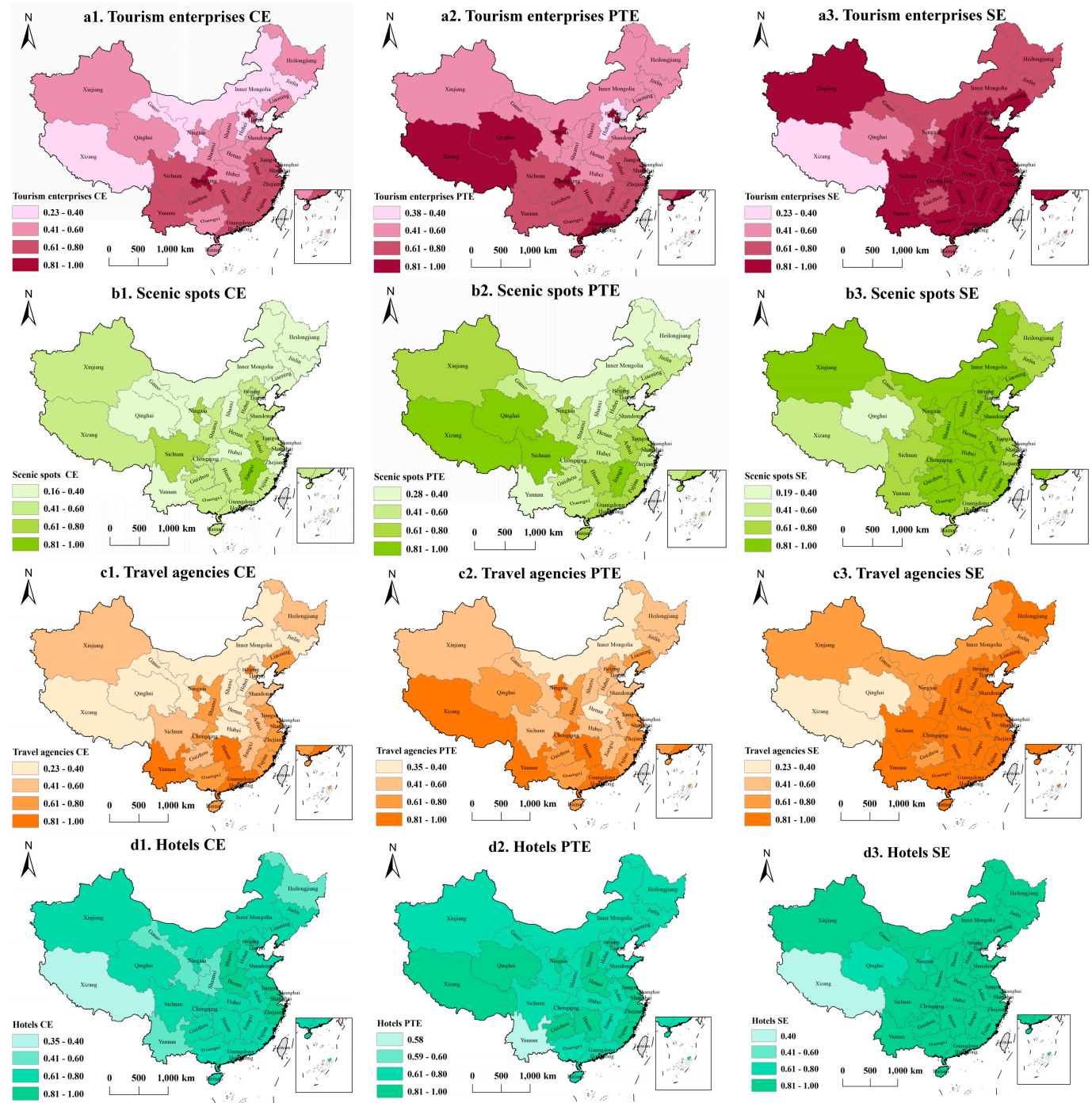

Figure 4. Efficiency values for tourism and sub-sectors enterprises of Chinese provinces between 2005 and 2014.

\subsubsection{Spatial Patterns in the TFPC and Efficiencies Change Indexes}

It was found that both TC and TFPC values for tourism enterprises generally increased over the period between 2005 and 2014. Specifically, values for the CEC, PTEC, and the SC were greater than one in one (Heilongiiang), six (Tianjin, Guangzhou, Hunan, Qinghai, Ningxia, and Heilongiiang), and one (Shanghai) provinces, respectively, reflective of an overall downward trend in all cases. In contract, TPC values between 2005 and 2014 were all greater than one, indicating that increases in TFP were largely caused by technological progress. The number of provinces with TPC and TFPC values higher than one for scenic spots comprised 29 and 26, respectively, while values for the CEC, PTC, and SEC were higher than this level in 17, 21, and 31 provinces, respectively. Provincial travel agency values for the TPC and TFPC were greater than one, while values for the CEC, PTEC, and SEC were greater than one in four provinces (Beijing, Shanghai, Chongqing, and Jilin), seven provinces (Beijing, Shanghai, Chongqing, Guizhou, Ningxia, Tibet, and Jilin), and three provinces (Beijing, Shanghai, and Chongqing), respectively. The provinces characterized by efficiency change index values more than one encompassed more than $80 \%$ of the whole country (Figure 5). 


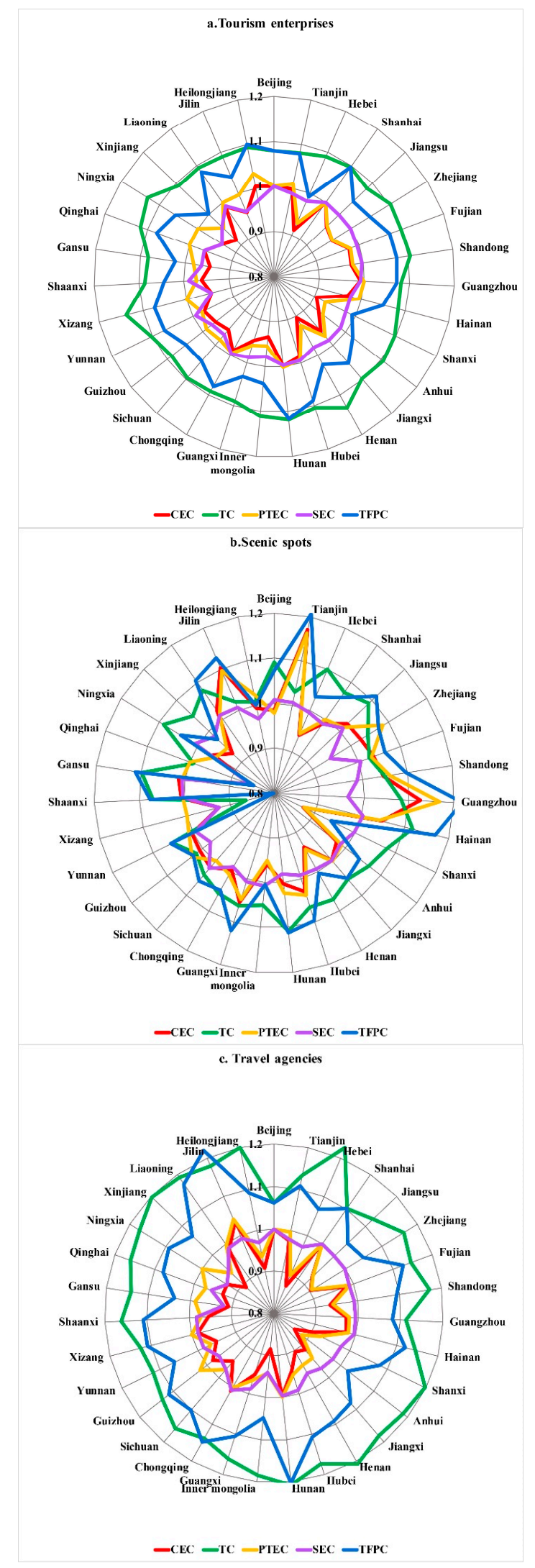

Figure 5. Cont. 


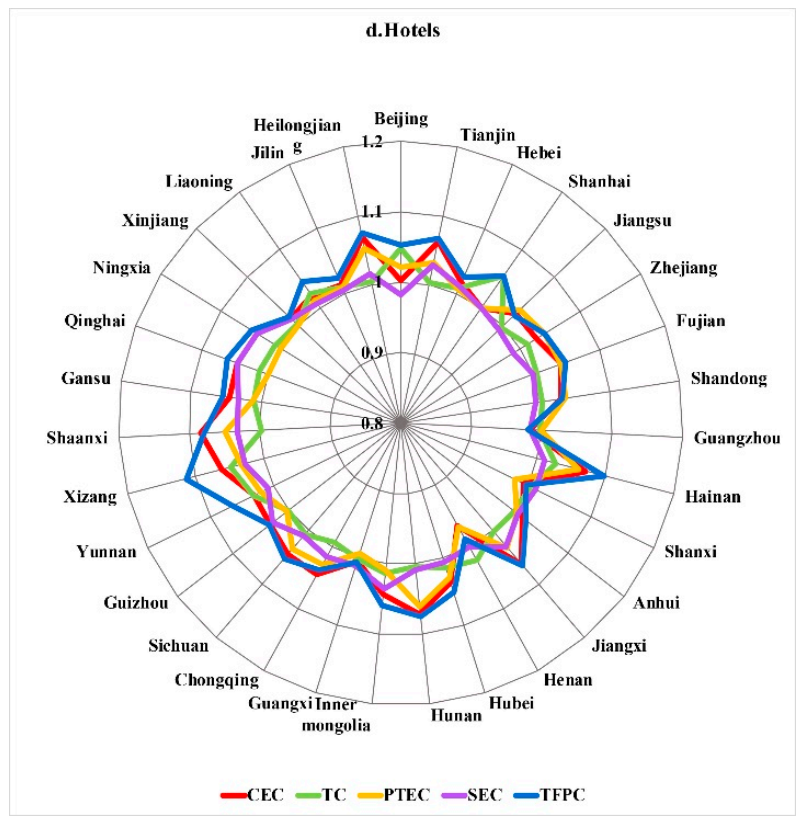

Figure 5. Efficiency change indexes of tourism enterprises of Chinese provinces between 2005 and 2014.

\subsubsection{Transfer of Center of Tourism Enterprise Efficiencies}

Based on the application of an ArcGIS center model, data from the four years 2005, 2008, 2011, and 2014 were selected to analyze the special direction and movement traces of CE, PTE, and SE values for tourism enterprises, scenic spots, travel agencies, and hotels. The results of this comparison show that the $\mathrm{CE}$ centers for tourism enterprises were mainly located at the junction between Henan and Hubei Provinces, and the overall movement trace tended to transfer rapidly towards the southeast coast over the period of this study. Data show that the center varied to a large extent between 2005 and 2008; the PTE centers for tourism enterprises were located at the junctions between Henan, Hubei, and Shaanxi, the movement trace was located towards the southeast coast as well as back to the northwest, and the center of gravity moved little overall. The SE center of tourism enterprises gradually moved towards the southeast coast, while the range at the same time is larger. Similarly, the CE center of scenic spots moved over a large range; this position moved in a southeast-to-northwest direction, with centers mainly located at the junction between Henan, Hubei, and Shaanxi Provinces. The PTE center of scenic spots also moved a great deal over the course of this study in a southeast-to-northwest direction with centers located in Hubei. The centers of scenic spot SE were located in Henan over the course of this study, with a small range of movement in an east-west direction. Data also show that travel agency CE centers were initially located in Henan Province, within the Hubei border region, and to the southeast, before moving south over time, while the PTE centers for this sector were initially located in the northwest of Hubei Province before first moving southeast and then in a southwestern direction. Similarly, the SE center for travel agencies was initially located in southern Henan Province but overall moved south over time, while the CE and PTE centers for hotels tended towards a southward movement. Data show that a movement trend towards Beijing-Tianjin-Hebei occurred in 2008, which may have been related to the 2008 Beijing Olympic Games. Indeed, the SE of hotels also tended to move westward after 2011; this might in part be due to the industrial transfer and the expansion of domestic hotel groups into the western region of the country. It is nevertheless generally the case that the spatial pattern of tourism enterprise evolution has been quite different to that of scenic spots, travel agencies, and hotels. These results therefore also show that the forces underlying the spatial pattern changes in scenic spots, travel agencies, and hotels were different (Figure 6). 


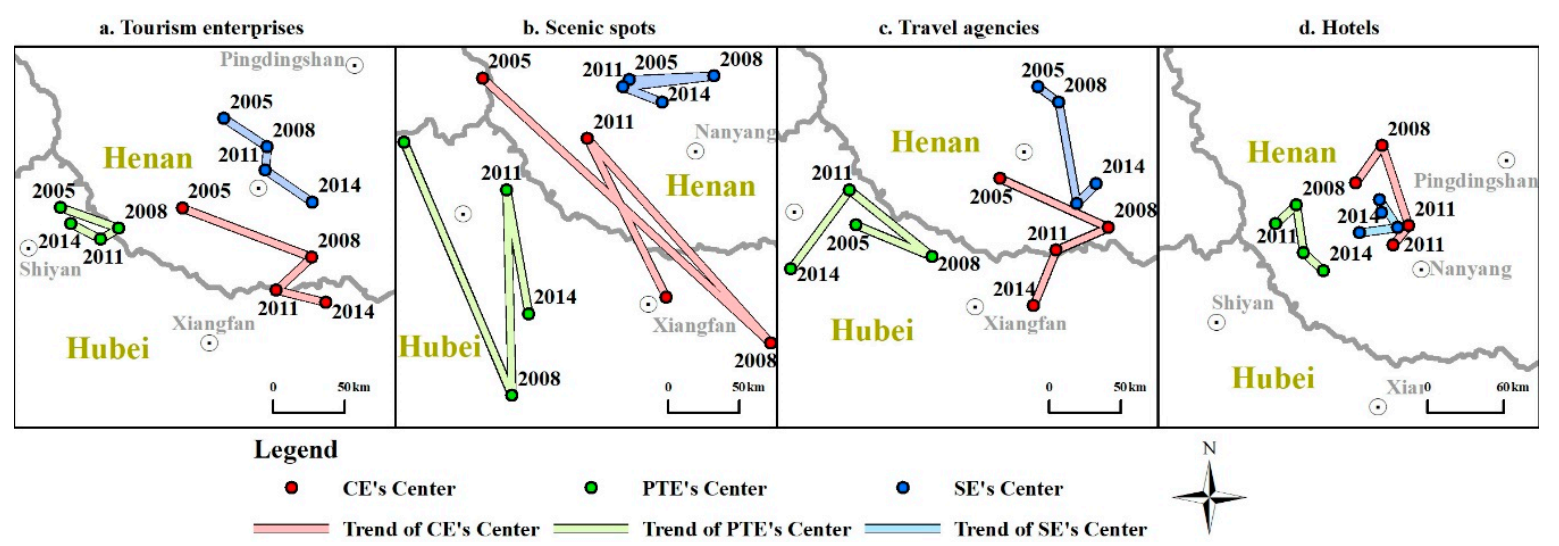

Figure 6. The transfer of the efficiencies center of tourism and sub-sectors enterprises between 2005 and 2014.

\subsection{Spatial Correlation Analysis of Tourism Enterprise Efficiencies}

\subsubsection{Global Spatial Autocorrelation Analysis}

As noted above, spatial correlations in CE values across the tourism sectors of 31 Chinese provinces between 2005 and 2014 were analyzed using Moran's I statistic. These comparisons show that Moran's I values for the $C E$ of tourism enterprises were greater than zero in each year sampled, and that in six years values were significant (i.e., $p<0.05$ ); this result is indicative of certain spatial agglomeration characteristics. Data show that values of the Moran's I statistic fluctuated greatly in different years in terms scenic spot $C E$ values; values were greater than zero in just three years where significance was attained and there was no spatial agglomeration overall. At the same time, Moran's I values for travel agency CEs between 2005 and 2009 were all greater than zero and passed the significance test, therefore exhibiting clear spatial agglomeration characteristics. However, most of these values were less than zero between 2011 and 2014, and so spatial agglomeration over this period was not obvious. Annual Moran's I values for hotels' CEs were also greater than zero a d significant over the five years of this study, which is indicative of spatial agglomeration (Table 1).

Table 1. Global Moran's I values for Chinese tourism enterprises CEs between 2005 and 2014.

\begin{tabular}{clcccccccccccc}
\hline \multirow{2}{*}{ Year } & \multicolumn{3}{c}{ Tourism Enterprises } & \multicolumn{3}{c}{ Scenic Spots } & \multicolumn{3}{c}{ Travel Agencies } & \multicolumn{3}{c}{ Hotels } \\
\cline { 2 - 12 } & Moran & $\boldsymbol{Z}$ & $\boldsymbol{p}$ & Moran & $\boldsymbol{Z}$ & $\boldsymbol{p}$ & Moran & $\boldsymbol{Z}$ & $\boldsymbol{p}$ & Moran & $\boldsymbol{Z}$ & $\boldsymbol{p}$ \\
\hline 2005 & 0.166 & 2.065 & 0.035 & -0.011 & 0.212 & 0.430 & 0.179 & 2.124 & 0.030 & 0.135 & 1.635 & 0.055 \\
2006 & 0.141 & 1.682 & 0.055 & -0.974 & -0.624 & 0.295 & 0.193 & 2.177 & 0.040 & 0.197 & 2.341 & 0.020 \\
2007 & 0.115 & 1.287 & 0.100 & -0.012 & 0.185 & 0.370 & 0.223 & 2.537 & 0.010 & 0.125 & 1.594 & 0.065 \\
2008 & 0.261 & 3.042 & 0.015 & 0.197 & 2.336 & 0.025 & 0.237 & 2.388 & 0.010 & 0.102 & 1.638 & 0.075 \\
2009 & 0.326 & 3.082 & 0.005 & -0.172 & -1.420 & 0.075 & 0.217 & 2.473 & 0.020 & 0.119 & 1.549 & 0.080 \\
2011 & 0.426 & 4.416 & 0.005 & 0.050 & 0.702 & 0.235 & 0.202 & 2.260 & 0.015 & 0.313 & 3.219 & 0.005 \\
2012 & 0.282 & 3.047 & 0.005 & 0.192 & 2.020 & 0.030 & -0.019 & 0.104 & 0.410 & 0.289 & 3.278 & 0.005 \\
2013 & 0.098 & 1.207 & 0.150 & 0.089 & 0.905 & 0.165 & -0.111 & -0.778 & 0.215 & 0.184 & 2.103 & 0.035 \\
2014 & 0.142 & 1.808 & 0.045 & 0.186 & 2.358 & 0.030 & 0.058 & 0.899 & 0.190 & 0.264 & 2.719 & 0.005 \\
\hline
\end{tabular}

\subsubsection{Local Spatial Autocorrelation Analysis}

Although global spatial autocorrelation of Moran's I index can be used to efficiently analyze the degree of tourism enterprise spatial agglomeration, this approach cannot reveal spatial correlation characteristics between provinces. To do this, it is necessary to analyze the spatial correlation characteristics of tourism enterprises $\mathrm{CE}$ values in each province using local spatial autocorrelation. The results show that the spatial heterogeneity of tourism enterprises is quite different across China 
and the spatial autocorrelation overall enterprises was also relatively high. We therefore only analyzed local spatial autocorrelation in this study based on CE values for tourism enterprises in 2005, 2008, 2011 and 2014. The results of this study reveal the presence of four categories, including a high-high agglomeration area of tourism enterprise CE values that are both high in these areas as well as in surrounding provinces. The second category revealed by this analysis comprises a high-low agglomeration area that includes high CE values for tourism enterprises in the provinces and low values in the surroundings, while the third category comprises a low-high agglomeration area. This group includes $C E$ values for tourism enterprises in agglomerated provinces that are low while their counterparts in surrounding areas are high. The fourth category consists of a low-low agglomeration area, where $C E$ values for tourism enterprises in agglomeration area provinces are low and those in surrounding provinces are also low. Cases where $p$-values are less than 0.05 passed a significance level test. Figure 7 shows the spatial distribution of these four categories.

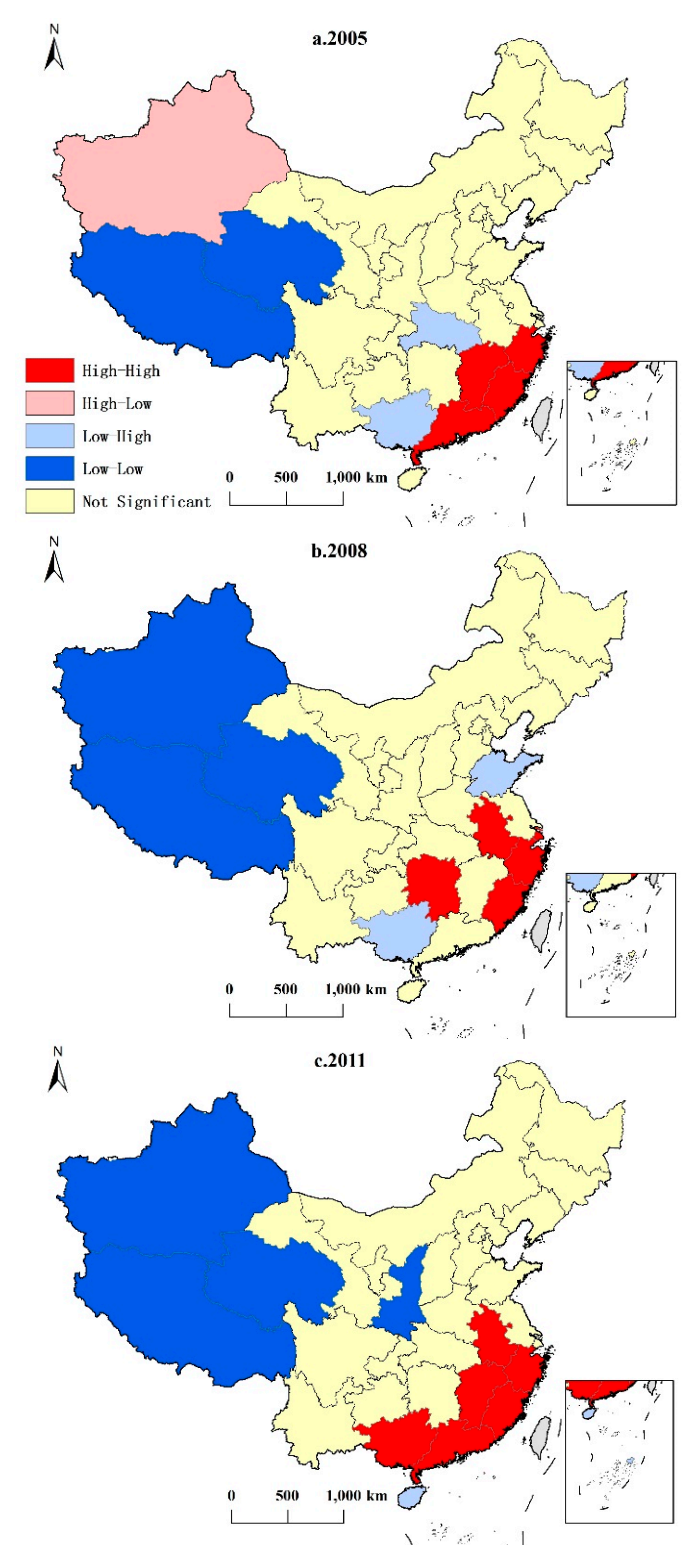

Figure 7. Cont. 


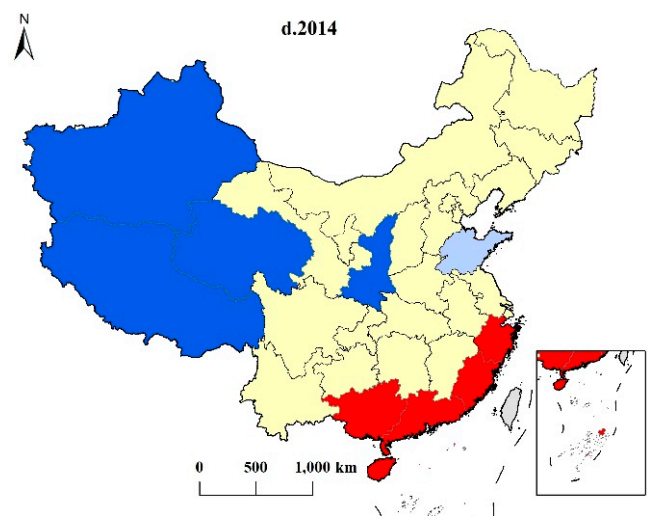

Figure 7. Local spatial correlation patterns in Chinese tourism enterprise CE values in 2005, 2008, 2011 and 2014.

The results show that high-high agglomeration areas are mainly concentrated in the southeastern coastal areas of China, trending from the east coast to the south. At the same time, low-low agglomeration areas are mainly concentrated in the northwest region of the country, while high-low and low-high agglomerations are fewer in number. Hainan Province, for example, has undergone a transition from a low correlation low-high to a high-high agglomeration area, while Guangxi Province has transitioned from a low-high to a high-high agglomeration area. Qinghai and Tibet always occur within low agglomeration areas, while Xinjiang has experienced a transition from high-low to low-low agglomeration, and Ningxia and Shaanxi have changed from non-significant spatial correlations to low-low agglomeration areas. Similarly, over the same period, both Jiangxi and Anhui have transformed from high-high agglomerations to non-significantly correlated areas. It is also noteworthy that most northern and central regions of China are characterized by insignificantly spatially correlated CE values for tourism enterprises; these results suggest that the Beijing-Tianjin-Hebei and central regions of China need to do more to fully realize their role as ties and bridges to the west as well as those of other regions with lower $\mathrm{CE}$ values in addition to developing tourism industries.

\subsection{The Driving Factors Analysis of Spatial Differentiation in Tourism Enterprise CE Values}

One of the aims of this paper was to analyze the various factors that drive the efficiencies of tourism enterprises from two points of-view, the macro-socioeconomic and meso-industrial environments, which characterize the development of tourism industry. The macro-socioeconomic environment that incubates the development of tourism enterprises mainly includes economic development level, industrial structure, location and transportation conditions, the degree to which a region has been opened to the outside world, and the level of available scientific and technological information. The meso-industrial environment of tourism enterprises can be measured by the level of industry-based human capital expressed in the form of tourism higher education level, and the state of industry marketization expressed as the level of tourism internationalization. The factors driving the spatial differentiation of tourism enterprise efficiencies were also analyzed in this study based on potential human capital, economic development, industrial structure, tourism internationalization and education, regional traffic conditions, the degree to which a region has been opened to the outside world, and available technological information. Based on previous research, in this paper, eight indicators (total population, per capita gross domestic product (GDP), the proportion of tertiary industry, international tourism receipts, the number of students within the industry, per capita road mileage, foreign investments at year-end, and per capita post and telecommunications) were chosen as the driving factors. According to the analysis steps of the Geotector (Equation (9)), the efficiencies of tourism enterprises values were disposed by grid point processing and typed conversion of index factors by natural fracture point method [53]. Each indicator was then divided into ten categories 
(Figure 8), and the contribution of each to the spatial differentiation of tourism enterprises' efficiencies at the level of scenic spots, travel agencies, and hotels was then evaluated (Table 2).

The analysis presented in this paper shows that the degree of opening to the outside world was the main underlying driving factor that affects CE, PTE, and TFPC values of tourism enterprises. In this context, potential human capital was the main factor driving both tourism enterprise PTE and SE values, while traffic conditions were the main factors driving SE and TFPC values. Second, traffic conditions and opening to the outside work ware the two main factors driving the efficiencies and TFPC values of scenic spots, while potential human resources were another main force. Third, the factors driving efficiencies and TFPC values for travel agencies were more complex. The level of tourism internationalization and scientific and technological information were the main factors driving CE values of travel agencies, while industrial structures and human capital were the main factors underlying PTE values of travel agencies. The results of this study show that potential human resources and the opening to the outside world were the main factors driving the SE of travel agencies, while traffic conditions and scientific and technological information were the main factors driving TFPC values of travel agencies. Fourth, the level of economic development and industrial structure were the main driving factors affecting the $\mathrm{CE}$ values of hotels, while the opening to the outside world and potential human resources were the main factors driving PTE, SE, and TFPC values of hotels. Thus, taking a comprehensive view, the degree of opening to the outside world is the most important factor driving the efficiencies of tourism enterprises, followed by traffic conditions, and potential human resources. The results also agree with the trade theory of classical economics, which purports the basic view that opening to the outside world can improve the development of a regional economy. At the same time, this theory can also explain the fact that the degree of opening to the outside world is an inherent requirement to develop tourism industry.
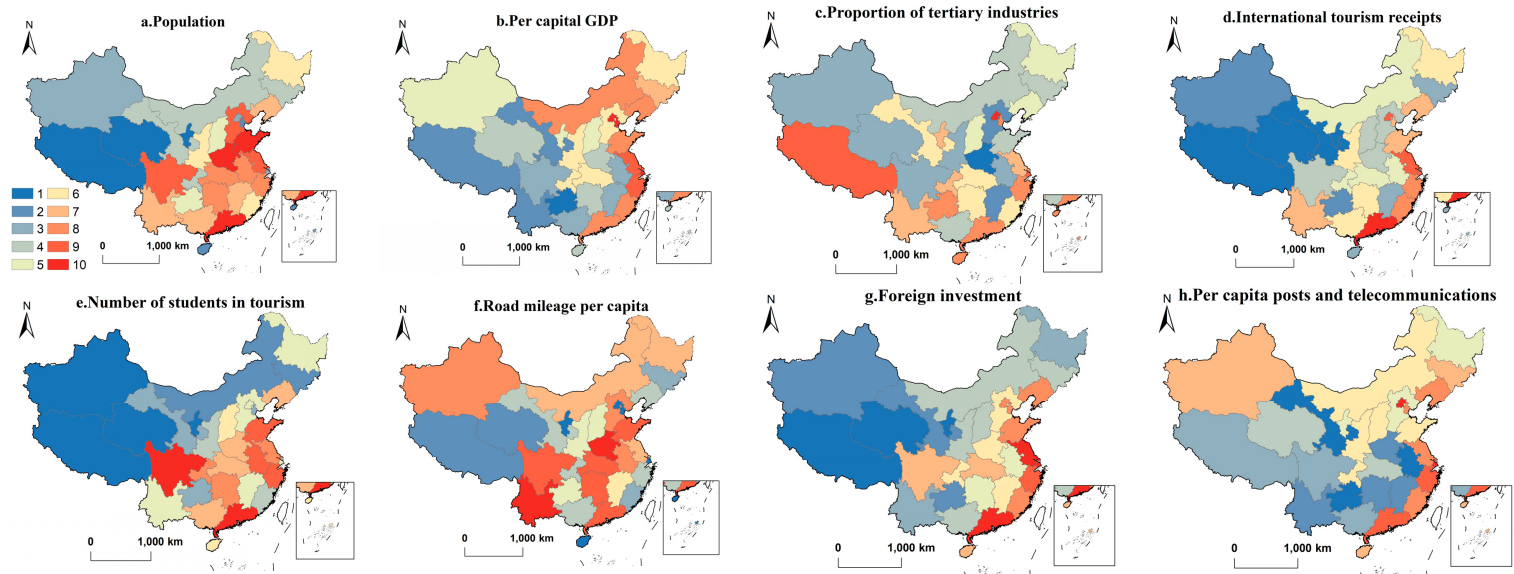

Figure 8. The spatial distribution of Geodetector indicator categories of tourism enterprise efficiencies. 
Table 2. Geodetector $q$ values for tourism enterprise efficiencies.

\begin{tabular}{|c|c|c|c|c|c|c|c|c|}
\hline Efficiencies & Population & $\begin{array}{l}\text { Per Capital } \\
\text { GDP }\end{array}$ & $\begin{array}{c}\text { Proportion of } \\
\text { Tertiary } \\
\text { Industries }\end{array}$ & $\begin{array}{c}\text { International } \\
\text { Tourism } \\
\text { Receipts }\end{array}$ & $\begin{array}{c}\text { Number of } \\
\text { Students in } \\
\text { Tourism }\end{array}$ & $\begin{array}{l}\text { Road Mileage } \\
\text { Per Capital }\end{array}$ & $\begin{array}{c}\text { Foreign } \\
\text { Investment }\end{array}$ & $\begin{array}{l}\text { Per Capita Posts and } \\
\text { Telecommunications }\end{array}$ \\
\hline Tourism enterprise $\mathrm{CE}$ & 0.5776 & 0.3905 & 0.5529 & 0.5494 & 0.5989 & 0.5359 & 0.6022 & 0.4223 \\
\hline PTE of tourism enterprises & 0.8221 & 0.4237 & 0.5789 & 0.5502 & 0.3456 & 0.7931 & 0.8404 & 0.0858 \\
\hline SE of tourism enterprises & 0.9340 & 0.4558 & 0.6804 & 0.7976 & 0.4889 & 0.9085 & 0.9038 & 0.3395 \\
\hline TFPC of tourism enterprises & 0.6439 & 0.5124 & 0.3375 & 0.5910 & 0.1830 & 0.6445 & 0.7110 & 0.1941 \\
\hline Scenic spot CE & 0.4220 & 0.3934 & 0.3874 & 0.3296 & 0.3754 & 0.5874 & 0.4822 & 0.4778 \\
\hline PTE of scenic spots & 0.8303 & 0.3733 & 0.7753 & 0.5475 & 0.6580 & 0.8668 & 0.8432 & 0.3801 \\
\hline SE of scenic spots & 0.7841 & 0.4183 & 0.2898 & 0.6176 & 0.2810 & 0.8291 & 0.7971 & 0.1326 \\
\hline TEPC of scenic spots & 0.8224 & 0.2776 & 0.7255 & 0.5959 & 0.6510 & 0.8936 & 0.7901 & 0.5878 \\
\hline Travel agency CE & 0.6248 & 0.1807 & 0.5555 & 0.6815 & 0.6281 & 0.5256 & 0.6187 & 0.6496 \\
\hline PTE of travel agencies & 0.5433 & 0.4350 & 0.8029 & 0.4693 & 0.3377 & 0.5108 & 0.5420 & 0.3409 \\
\hline SE of travel agencies & 0.9315 & 0.4792 & 0.6567 & 0.8679 & 0.5970 & 0.8841 & 0.9187 & 0.4118 \\
\hline TEPC of travel agencies TEPC of & 0.4444 & 0.4082 & 0.1174 & 0.3289 & 0.2674 & 0.4886 & 0.2422 & 0.4679 \\
\hline hotel $C E$ values & 0.4653 & 0.6771 & 0.6554 & 0.4198 & 0.2854 & 0.3306 & 0.4954 & 0.4023 \\
\hline PTE of hotels & 0.7686 & 0.4147 & 0.3355 & 0.4920 & 0.4190 & 0.5724 & 0.7857 & 0.3005 \\
\hline SE of hotels & 0.8589 & 0.4601 & 0.8477 & 0.6605 & 0.3620 & 0.8497 & 0.8499 & 0.2794 \\
\hline TEPC of hotels & 0.7339 & 0.5220 & 0.5246 & 0.5783 & 0.1601 & 0.5816 & 0.5810 & 0.2737 \\
\hline
\end{tabular}




\section{Conclusions and Future Suggestions}

\subsection{Conclusions}

(1) The efficiency of Chinese tourism enterprises was low between 2005 and 2014, and there is much space to improve in the future. The data presented in this paper showed that CE and PTE values for tourism enterprises, scenic spots, travel agencies, and hotels were not high, and overall tended to trend downwards. At the same time, although SE values were elevated, these have also tended to exhibit a downward trend in recent years, alongside TFPC values, and, while the contribution of SE to CE is limited, values of the latter for tourism enterprises have nevertheless remained at a relatively low level. Data also imply that the main contributor to the development of Chinese tourism in recent years has been an increase in investment, rather than improvements in technological progress and efficiencies. Chinese tourism enterprises have not been key market actors in this development process and have simply not stimulated the market; and a lot of space remains for the promotion of tourism enterprises as components of market operation.

(2) Data show that SE values for tourism enterprises and sub-sectors of Chinese provinces tended to be higher than other efficiencies, and that technological progress and TFP growth were more obvious. Thus, the efficiency levels of tourism enterprises in both Beijing and Shanghai led those of the whole country, and Chongqing, Tibet, Qinghai, and Ningxia in the west have boasted obvious advantages. Similarly, in terms of the efficiency of scenic spots, Jiangxi had obvious advantages, and the most efficient travel agencies were in Beijing, Shanghai, and Guangdong. The growth in the efficiency of travel agencies with TFP values in Jilin Province have also been distinguished by obvious advantages, while provinces with highly efficient hotels were mainly concentrated in developed eastern coastal areas of China. The CV analysis presented in this paper showed that there would likely be an increase trend in the future; the results showed that differences in CE values for scenic spots had gradually narrowed, while differences in CE values for travel agencies had gradually increased, and those for hotels had decreased.

(3) The centers of efficiency for tourism enterprises mainly moved over this period along a transect from southeast-to-northwest direction, indicating that southeastern coastal areas of China have exerted a certain siphon effect on the development of tourism enterprises. The ArcGIS center analysis outlined in this study revealed that the center of efficiency for tourism enterprises within China was mainly located on the border between Henan and Hubei provinces between 2005 and 2014, and that the centers of tourism enterprises, travel agencies, and hotels moved by about $100 \mathrm{~km}$ over this time. The range of movement seen in the hotels center of efficiency was the smallest within these data, while that of scenic spots was the largest.

(4) The spatial pattern of the efficiency of tourism enterprises was basically consistent with the pattern, high in the east and low in the west, of the overall level of regional economic development. The efficiency and growth of tourism enterprises in eastern China tended to be enhanced and more rapid than in other areas, although the SE growth of hotels had remained at a lower level. Most of the efficiencies in tourism enterprises in the center of China have also been higher than those seen in the west and northeast, including the TFPC values for travel agencies, CE and SE values for scenic spots, and SE values for hotels which had all been higher than those in the east of the country. Although efficiencies tended to be low in both the northeast and west of China, data revealed several advantages in values of the PTE, PTEC, and TP. However, the spatial pattern of the TFPC of tourism enterprises was not consistent with the pattern, high in the west and low in the east, on the TFPC of economic development of China. This also showed that the development of tourism enterprises was related to the economic and social development, but the interaction mechanism of the them was complex, and not a simple causation.

(5) The global spatial autocorrelation analysis results showed that CE values for tourism enterprises presented certain spatial agglomeration characteristics, but these were not particularly significant. Tourism enterprise CE values in southeastern coastal areas were 
relatively high over the period of this study, for example, as were those of surrounding provinces, leading to a certain spatial agglomeration effect. In recent years, Xinjiang Province has enjoyed several advantages within western China in terms of tourism development and has therefore slowly developed enterprises, while the west of China has tended to miss out on efficiency advantage areas in this context. The results showed no significant correlation in tourism enterprise $\mathrm{CE}$ values between the north and center of China, further illustrating the lack of cooperation in this area among regions of the country. Thus, it is difficult to form the resultant force of development, and also difficult to be the bridge between the southeast coast and the Centre and West of China.

(6) The Geodetector analysis presented the opening to outside world, potential human capital and traffic conditions were the main factors driving the efficiency of Chinese tourism enterprises. The degree of opening to the outside world was the main factor driving efficiencies in tourism enterprises (i.e., based on the number of times that Geodetector $q$ value for this variable were ranked first). At the same time, the results of this analysis also showed that potential human capital was the driving force that exerts the greatest degree of influence overall (i.e., maximal sum of $q$ values), and that traffic conditions were also important. The factors that have exerted the least influence on this relationship were science and information technology level, followed by the extent of tourism education and economic development. It was generally the case that economic development was positively related to tourism income, and that the level of education and science and information technology usually be the key forces driving improvements in the efficiencies of tourism enterprises. However, it is shown that the efficiencies of tourism enterprises remained at a relatively low level between 2005 and 2014. The forces that should have been expected to play leading roles did not actually act to improve the efficiency of Chinese tourism.

\subsection{Future Suggestions}

(1) The characteristics of tourism sub-sector efficiency spatial differentiation revealed that there were obvious advantages to these initiatives in both the east and center of China, but that the efficiency levels of most provinces in these regions had not yet reached a relative level of 0.8 . Thus, going forward, advanced international management techniques for tourism enterprises should be fostered and developed to further enhance the efficiencies of tourism enterprises in the east and center of China and to enhance the leading role of those in the country. Indeed, relative advantages on the TFPC and efficiencies' change index of tourism enterprises in the northeast and west of China means that there is huge potential for the development of regional tourism enterprises given the same input. It will be necessary to strengthen the support for tourism enterprises in northeast and west with the advantages of Beijing and Shanghai. To increase investment and the technology transfer of human capital, management, service, and information construction, China should improve the efficiency of tourism enterprises in the northeast and west of China, promote the development of the tourism market, increase the output value and promote tourism as an important initiative to boost industrial transformation and structural upgrades in northeastern and western China.

(2) Spatial agglomeration effects in the efficiencies of tourism enterprises in eastern China can be further improved in the future via the creation, layout, and optimization of high-speed traffic networks including high-speed railways and expressways. The development of "The Belt and Road" initiative and Silk Road international travel routes are likely to support tourism development in Shaanxi, Xinjiang, and Sichuan provinces as well their counterparts, leading to several advantages. These developments are also likely to form the tourism development growth pole towards western region, and promote the transformation of this agglomeration area of tourism enterprise efficiencies from low-low to low-high and high-high. At the same time, the central region of China should also act to strengthen cooperation with other areas and integrate tourism routes, mobile Internet clients, and marketing activities to realize a linking and bridging 
role in the development of regional tourism enterprises. Regional cooperation should also be strengthened between northeastern and northern China; thus, the Beijing-Tianjin-Hebei region should be promoted as leading for tourism and tourism enterprises development, promoting cooperation among tourism enterprises and strengthening the integration of tourism market. Through industrial agglomeration, the spatial agglomeration could be realized, and the resultant force of regional development well be formed.

(3) The efficiency of tourism enterprises can be improved in the future by increasing the level to which regions are opening to the outside world, as well as by taking advantage of potential human capital and traffic conditions. At the same time, according to the differences of production and supply process and consumption channels of scenic spots, travel agencies and star hotels, by improving their respective main driving factors, the efficiency of the tourism enterprises cloud be improved. Similarly, correlations between tourism enterprises and the level of economic development, tourism education, and science and technology information should also be enhanced while the relationship with regional economic development can also be strengthened via the integration of regional related industries through the integration of tourism with other industries. Thus, via an in-depth study of the scale and structure of talent demand within tourism enterprises, educational institutions can train new talent to feed into this area and remedy shortcomings in human resources within these enterprises and achieve the goal of improving productivity through education. These solutions will enhance the construction level of tourism information, improve the application of modern technology at scenic spots, enhance traditional travel agencies and hotels, and lead to overall improvements in the efficiency of Chinese tourism enterprises.

(4) Supply side reforms to the Chinese tourism industry should be focused on technological progress and improving the technical efficiency of enterprises, with promoting organizational and management innovations in the context of modern science and technology. These suggestions will improve the level of modern information technology application, including mobile Internet, cloud computing, and the Internet of things. Exploring the management and operation mode of travel agencies and scenic spots in the era of large data and mobile Internet, drawing on the experience of international hotel group's global integration strategy, the potential economic efficiency and economic output capacity of tourism enterprises should be fully released. These solutions will act to promote the development of the Chinese tourism market, improve the overall output value, and enhance the economic value of these sectors while at the same time upgrading and transforming local industrial structures.

Acknowledgments: This work was funded by Science \& Technology Basic Resources Investigation Program of China (2017FY101304). The authors thank the editor and the reviewers' guidance for this manuscript.

Author Contributions: Bing Xia, Suocheng Dong, and Duoxun Ba conceived and designed the experiments; Bing Xia, Yu Li, Fujia Li, Zehong Li and Minyan Zhao collected and processed the data; Bing Xia, Suocheng Dong, and Haimeng Liu analyzed the data; and Bing Xia wrote the paper.

Conflicts of Interest: The authors declare no conflict of interest.

\section{References}

1. World Tourism Organization (UNWTO). UNWTO Annual Report 2016; World Tourism Organization: Madrid, Spain, 2017.

2. World Tourism Organization (UNWTO). UNWTO Tourism Highlights, 2016 Edition; World Tourism Organization: Madrid, Spain, 2016.

3. Martin, J.C.; Mendoza, C.; Roman, C. A DEA Travel-Tourism Competitiveness Index. Soc. Indic. Res. 2017, 130, 937-957. [CrossRef]

4. Zhang, L.; Botti, L.; Petit, S. Destination performance: Introducing the utility function in the mean-variance space. Tour. Manag. 2016, 52, 123-132. [CrossRef] 
5. Corne, A. Benchmarking and tourism efficiency in France. Tour. Manag. 2015, 51, 91-95. [CrossRef]

6. Man, D.; Zhang, H. The Study of DEA Application in Tourism City: A Case for Members of the World Tourism City Federation in China; Springer: Berlin, Germany, 2015; pp. 831-835.

7. Liu, J.; Zhang, J.; Fu, Z. Tourism eco-efficiency of Chinese coastal cities-Analysis based on the DEA-Tobit model. Ocean Coast. Manag. 2017, 148, 164-170. [CrossRef]

8. Oender, I.; Wober, K.; Zekan, B. Towards a sustainable urban tourism development in Europe: The role of benchmarking and tourism management information systems-A partial model of destination competitiveness. Tour. Econ. 2017, 23, 243-259. [CrossRef]

9. Ting, C.; Wei, P. Tourism Management Efficiency Maximization Model Based on the AHP and Grey Theory Analysis; Science \& Research Central Ltd.: Newark, NJ, USA, 2017; pp. 51-57.

10. Yu, C.; Li, M. An Efficiency Evaluation and a Regional Variance Analysis of the Provincial Forest Park Tourism; CRC Press-Taylor \& Francis Group: Boca Raton, FL, USA, 2016; pp. 207-211.

11. Goncalves, O. Efficiency and productivity of French ski resorts. Tour. Manag. 2013, 36, 650-657. [CrossRef]

12. Cao, F.; Huang, Z.; Jin, C.; Xu, M. Chinese National Scenic Areas' Tourism Efficiency: Multi-scale Fluctuation, Prediction and Optimization. Asia Pac. J. Tour. Res. 2016, 21, 570-595. [CrossRef]

13. Cuccia, T.; Guccio, C.; Rizzo, I. The effects of UNESCO World Heritage List inscription on tourism destinations performance in Italian regions. Econ. Modell. 2016, 53, 494-508. [CrossRef]

14. Ben Aissa, S.; Goaied, M. Performance of Tourism Destinations: Evidence from Tunisia. J. Hosp. Tour. Res. 2017, 41, 797-822. [CrossRef]

15. Huang, C.W.; Chen, H.Y.; Ting, C.T. Using a network data envelopment analysis model to assess the efficiency and effectiveness of cultural tourism promotion in Taiwan. J. Travel Tour. Mark. 2017, 34, 1274-1284. [CrossRef]

16. Eras, J.J.C.; Santos, V.S.; Gutierrez, A.S.; Plasencia, M.A.G.; Haeseldonckx, D.; Vandecasteele, C. Tools to improve forecasting and control of the electricity consumption in hotels. J. Clean. Prod. 2016, 137, 803-812. [CrossRef]

17. Tumamao-Guittap, G.S.; Napalang, M.S.G. Unlocking the Human Dimension of Energy Efficiency and Conservation: The Case of Tourist Accommodation Providers in Coron, Palawan in the Philippines. In Green Urbanism; Amer, M.S., Naselli, F., Pollice, F., Ghoneem, M.Y., Eds.; Elsevier: Amsterdam, The Netherlands, 2017; Volume 37, pp. 483-494.

18. Gabarda-Mallorqui, A.; Garcia, X.; Ribas, A. Mass tourism and water efficiency in the hotel industry: A case study. Int. J. Hospitality Manag. 2017, 61, 82-93. [CrossRef]

19. Pablo-Romero, M.P.; Sanchez-Braza, A.; Sanchez-Rivas, J. Relationships between Hotel and Restaurant Electricity Consumption and Tourism in 11 European Union Countries. Sustainability 2017, 9, 14. [CrossRef]

20. Del Pablo-Romero, M.P.; Pozo-Barajas, R.; Sanchez-Rivas, J. Relationships between Tourism and Hospitality Sector Electricity Consumption in Spanish Provinces (1999-2013). Sustainability 2017, 9, 480. [CrossRef]

21. Chang, H.H. Which one helps tourists most? Perspectives of international tourists using different navigation aids. Tour. Geogr. 2015, 17, 350-369. [CrossRef]

22. Fuentes, R.; Fuster, B.; Lillo-Banuls, A. A three-stage DEA model to evaluate learning-teaching technical efficiency: Key performance indicators and contextual variables. Expert Syst. Appl. 2016, 48, 89-99. [CrossRef]

23. Ohe, Y. Assessing Managerial Efficiency of Educational Tourism in Agriculture: Case of Dairy Farms in Japan. Sustainability 2017, 9, 1931. [CrossRef]

24. Huang, C. Assessing the performance of tourism supply chains by using the hybrid network data envelopment analysis model. Tour. Manag. 2018, 65, 303-316. [CrossRef]

25. Stoian, R.G.; Muresan, M.L. Dynamics and efficiency of events tourism, factors in global economic growth. In Proceedings of the CBU International Conference on Innovations in Science and Education, Prague, Czech Republic, 23-25 March 2016; Hajek, P., Sahota, T., Jones, M.A., Eds.; Central Bohemia University: Prague, Czech Republic, 2016; pp. 73-78.

26. Serrano, M.D.T. Communicative efficiency of websites in the case of the tourism management of the World Heritage sites in Spain. Bol. Asoc. Geogr. Esp. 2016, 323-346. [CrossRef]

27. Alberca-Oliver, P.; Rodriguez-Oromendia, A.; Parte-Esteban, L. Measuring the efficiency of trade shows: A Spanish case study. Tour. Manag. 2015, 47, 127-137. [CrossRef] 
28. Gallarza, M.G.; Arteaga, F.; Del Chiappa, G.; Gil-Saura, I. Value dimensions in consumers' experience: Combining the intra- and inter-variable approaches in the hospitality sector. Int. J. Hosp. Manag. 2015, 47, 140-150. [CrossRef]

29. Asgarpour, R.; Hamid, A.B.A.; Sulaiman, Z.B.; Asgari, A.A. Efficiency or Inefficiency of Customer Satisfaction as One of the Main Antecedents of Customer Loyalty in Tourism and Hospitality Industry. Adv. Sci. Lett. 2015, 21, 1842-1844. [CrossRef]

30. Shieh, H.S.; Hu, J.L.; Liu, T.Y. An environment-adjusted dynamic efficiency analysis of international tourist hotels in Taiwan. Curr. Issues Tour. 2017, 20, 1749-1767. [CrossRef]

31. Parte-Esteban, L.; Alberca-Oliver, P. Determinants of technical efficiency in the Spanish hotel industry: Regional and corporate performance factors. Curr. Issues Tour. 2015, 18, 391-411. [CrossRef]

32. Cordero, J.M.; Tzeremes, N.G. Evaluating hotel productivity growth in Balearic and Canary islands. Tour. Econ. 2017, 23, 1146-1154. [CrossRef]

33. Koksal, C.D.; Aksu, A.A. Efficiency evaluation of A-group travel agencies with data envelopment analysis (DEA): A case study in the Antalya region, Turkey. Tour. Manag. 2007, 28, 830-834. [CrossRef]

34. Fragoudaki, A.; Giokas, D. Airport performance in a tourism receiving country: Evidence from Greece. J. Air Transp. Manag. 2016, 52, 80-89. [CrossRef]

35. Fragoudaki, A.; Giokas, D.; Glyptou, K. Efficiency and productivity changes in Greek airports during the crisis years 2010-2014. J. Air Transp. Manag. 2016, 57, 306-315. [CrossRef]

36. Herrero-Prieto, L.; Gomez-Vega, M. Cultural resources as a factor in cultural tourism attraction: Technical efficiency estimation of regional destinations in Spain. Tour. Econ. 2017, 23, 260-280. [CrossRef]

37. Taheri, H.; Ansari, S. Measuring the relative efficiency of cultural-historical museums in Tehran: DEA approach. J. Cult. Herit. 2013, 14, 431-438. [CrossRef]

38. Assaf, A.G.; Josiassen, A. Frontier Analysis: A State-of-the-Art Review and Meta-Analysis. J. Travel Res. 2016, 55, 612-627. [CrossRef]

39. Assaf, A.G. Benchmarking the Asia Pacific tourism industry: A Bayesian combination of DEA and stochastic frontier. Tour. Manag. 2012, 33, 1122-1127. [CrossRef]

40. Sun, J.; Zhang, J.; Zhang, J.; Ma, J.; Zhang, Y. Total Factor Productivity Assessment of Tourism Industry: Evidence from China. Asia Pac. J. Tour. Res. 2015, 20, 280-294. [CrossRef]

41. Cuccia, T.; Guccio, C.; Rizzo, I. UNESCO sites and performance trend of Italian regional tourism destinations: A two-stage DEA window analysis with spatial interaction. Tour. Econ. 2017, 23, 316-342. [CrossRef]

42. Li, R.; Guo, Q.; Wu, D.; Yin, H.; Zhang, H.; Zhu, T. Spatial characteristics of development efficiency for urban tourism in eastern China: A case study of six coastal urban agglomerations. J. Geogr. Sci. 2014, 24, 1175-1197. [CrossRef]

43. Figueroa, V.; Herrero, L.C.; Baez, A.; Gomez, M. Analysing how cultural factors influence the efficiency of tourist destinations in Chile. Int. J. Tour. Res. 2018, 20, 11-24. [CrossRef]

44. Guccio, C.; Lisi, D.; Martorana, M.; Mignosa, A. On the role of cultural participation in tourism destination performance: An assessment using robust conditional efficiency approach. J. Cult. Econ. 2017, 41, 129-154. [CrossRef]

45. Tsionas, E.G.; Assaf, A.G. Short-run and long-run performance of international tourism: Evidence from Bayesian dynamic models. Tour. Manag. 2014, 42, 22-36. [CrossRef]

46. Assaf, A.G.; Tsionas, E.G. Incorporating destination quality into the measurement of tourism performance: A Bayesian approach. Tour. Manag. 2015, 49, 58-71. [CrossRef]

47. Zha, J.P.; Li, Z.Y. Drivers of tourism growth: Evidence from China. Tour. Econ. 2017, 23, 941-962. [CrossRef]

48. Assaf, A.G.; Oh, H.; Tsionas, M. Bayesian Approach for the Measurement of Tourism Performance: A Case of Stochastic Frontier Models. J. Travel Res. 2017, 56, 172-186. [CrossRef]

49. Yi, T.; Liang, M. Evolutional Model of Tourism Efficiency Based on the DEA Method: A Case Study of Cities in Guangdong Province, China. Asia Pac. J. Tour. Res. 2015, 20, 789-806. [CrossRef]

50. Oliveira, R.; Pedro, M.I.; Marques, R.C. Efficiency and its determinants in Portuguese hotels in the Algarve. Tour. Manag. 2013, 36, 641-649. [CrossRef]

51. Ohe, Y.; Peypoch, N. Efficiency analysis of Japanese Ryokans: A window DEA approach. Tour. Econ. 2016, 22, 1261-1273. [CrossRef]

52. Pa, N.C.; Hassan, S.; Husin, N.S.; Ban, A. Productive Practices of Hotel Management System Using Usability Approach: A Case Study. Adv. Sci. Lett. 2016, 22, 1905-1908. [CrossRef] 
53. Wang, J.; Xu, C. Geodetector: Principle and prospective. Acta Geogr. Sin. 2017, 72, 116-134.

54. Banker, R.D.; Charnes, A.; Cooper, W.W. Some Models for Estimating Technical and Scale Inefficiencies in Data Envelopment Analysis. Manag. Sci. 1984, 30, 1078-1092. [CrossRef]

55. Charnes, A.; Cooper, W.W.; Rhodes, E. Measuring the efficiency of decision making units. Eur. J. Oper. Res. 1978, 2, 429-444. [CrossRef]

56. Malmquist, S. Index numbers and indifference curves. Trab. Estad. 1953, 4, 209-242. [CrossRef]

57. Caves, D.W.; Christensen, L.R.; Diewert, W.E. The economic-theory of index numbers and the measurement of input, output, and productivity. Econometrica 1982, 50, 1393-1414. [CrossRef]

58. Färe, R.; Crosskopf, S.; Lovell, C.A.K. Production Frontiers; Cambridge University Press: Cambridge, UK, 1994.

59. Anselin, L. Local Indicators of Spatial Association-LISA. Geogr. Anal. 1995, 27, 93-115. [CrossRef]

(C) 2018 by the authors. Licensee MDPI, Basel, Switzerland. This article is an open access article distributed under the terms and conditions of the Creative Commons Attribution (CC BY) license (http:/ / creativecommons.org/licenses/by/4.0/). 